\title{
El procesamiento de los cultivos autóctonos como alternativa microempresarial
}

\section{The processing of indigenous crops as a microenterprise alternative}

Pablo Antonio Abrigo Córdova

Universidad Internacional del Ecuador, Ecuador

Autor por Correspondencia: egtmaloja@gmail.com

Fecha de recepción: 31 de Enero de 2017 - Fecha de aceptación: 20 de Marzo de 2017

Resumen: El presente artículo pretende conocer el manejo de procesos agroindustriales para mejorar la calidad, aceptabilidad y prolongar el tiempo de almacenamiento y posterior consumo de los cultivos autóctonos, especialmente el melloco (Ullucus tuberosus Loz.), para ello se realizaron análisis, diagnósticos, aplicación de encuestas y entrevistas para saber su aceptabilidad en el mercado local. Según Abrigo (2016) en su estudio realizado al cultivo, manifiesta que la variedad blanca de melloco tiene el menor porcentaje de humedad, en relación a la amarilla y verde, siendo una característica propicia para procesar éste tubérculo. Una vez conocida la realidad se planteó la investigación que tuvo como propósito recomendar al campesino y habitantes en general la diversidad de usos desconocidos, respondiendo a una necesidad sentida de los productores para aumentar el valor agregado en las zonas rurales principalmente donde cultiva este tubérculo. La fase de procesamiento se realizó en el Laboratorio del Área de Pequeñas Industrias (UNL) donde se elaboraron mermeladas de melloco con frutos de uvilla y babaco con relaciones de pulpa / azúcar 55 / 45; hojuelas y harina de melloco obtenidas con un espesor adecuado de rodajas $(0,3 \mathrm{~cm})$ y un tiempo de secado óptimo de 70 grados centígrados, para los tres casos se realizaron cálculos de la materia prima y se desarrollaron diagramas de flujo para cada proceso. Las mejores características organolépticas correspondieron a las mermeladas de melloco con frutos de babaco, llegando su costo de producción a 0,93 USD, suponiendo su aceptabilidad por el bajo costo en relación a las mermeladas de melloco con frutos de uvilla que fue de 0,99 USD. Las formulaciones hechas de harina de melloco, se las realizó en base a comparaciones efectuadas con diferentes clases de harina existentes en el mercado, dando como resultado las mejores características organolépticas las elaboradas con harina de melloco, cuyo costo de fabricación llegó a 5,62 USD el kilo. Los envases utilizados para la presentación de las mermeladas así como las fundas de alta densidad para las harinas, estuvieron acordes a su calidad. Para determinar la aceptabilidad de los derivados se partió de los datos estadísticos del INEC, se realizó una estimación a las personas que acudieron a los mercados y supermercados para determinar la población y muestra, aplicando encuestas a 497 personas consumidoras, lo que permitió establecer la demanda potencial del cultivo, la comercialización y la publicidad y propaganda, con lo que se pudo realizar la proyección hasta cinco años siguientes. Para realizar la comercialización se diseñaron dos canales apropiados, resultando beneficiosos para que el agricultor obtenga rubros económicos aceptables. Para la transferencias de tecnologías se realizó eventos en la ciudad de Loja, contando con varias personas, a las cuales se les entrego productos para que den sus apreciaciones (características organolépticas) y hojas volantes (tríptico), demostrando gran interés por el rescate y fomento del cultivo y sus derivados a nivel comercial.

Palabras Clave: cultivos autóctonos; melloco; procesamiento; valor agregado; características organolépticas 
Abstract: This article aims to know the management of agroindustrial processes to improve the quality, acceptability and prolong the time of storage and subsequent consumption of native crops, especially melloco (Ullucus tuberosus Loz.), for which analyzes, diagnoses, Application of surveys and interviews to know its acceptability in the local market. According to Abrigo (2016) in his study to the crop, he states that the white variety of melloco has the lowest percentage of moisture, relative to the yellow and green, being a propitious feature to process this tuber. Once the reality was known, the research aimed at recommending the peasants and inhabitants in general the diversity of unknown uses, responding to a felt need of producers to increase the value added in rural areas mainly where this tuber cultivates. The processing phase was carried out in the Laboratory of the Small Industries Area (UNL), where melloco jams were made with uvilla and babaco fruits with pulp / sugar ratios 55/45; flakes and flour made of melloco obtained with a suitable thickness of slices $(0.3 \mathrm{~cm})$ and an optimum drying time of 70 degrees centigrade, for the three cases were made calculations of the raw material and flow diagrams were developed for each process. The best organoleptic characteristics corresponded to the melloco jams with babaco fruits, reaching its production cost to 0,93 USD, assuming its acceptability for the low cost in relation to melloco jams with uvilla fruits that was 0.99 USD. The formulations made of melloco flour were made on the basis of comparisons made with different kinds of flour on the market, resulting in the best organoleptic characteristics made with melloco flour, whose manufacturing cost reached USD 5.62 a kilo. The packaging used for the presentation of the jams as well as the high density cases for the flour, were in accordance with its quality. In order to determine the acceptability of the derivatives, the statistical data of the INEC were used, an estimate was made to the people who went to the markets and supermarkets to determine the population and sample, applying surveys to 497 consumers, which allowed to establish the demand Potential of cultivation, commercialization and advertising and propaganda, with which the projection could be made up to five years later. In order to carry out the commercialization, two appropriate channels were designed, being beneficial for the farmer toobtainoacceptableoeconomicoitems. For the transfer of technology events were held in the city of Loja, with several people, who were given products to give their appreciations (organoleptic characteristics) and leaflets (triptych), showing great interest in the rescue and development of the crop and its derivatives at commercial level.

Key words: autochthonous crops; melloco; processing; added value; organoleptic characteristics

\section{Introducción}

Uno de los terceros objetivos del Plan Nacional del Buen vivir (sumak kawsay) que plantea nuestro país el Ecuador es "Mejorar la calidad de vida de la población" (SENPLADES, 2013). La calidad de vida empieza por el derecho al Buen Vivir: agua, alimentación, salud, educación y vivienda, como requisito para lograr el fortalecimiento de capacidades y potencialidades individuales y sociales (Abrigo, 2016).

La Constitución, en el artículo 66, establece "el derecho a una vida digna, que asegure la salud, alimentación y nutrición, agua potable, vivienda, saneamiento ambiental, educación, trabajo, empleo, descanso y ocio, cultura física, vestido, seguridad social y otros servicios sociales necesarios". Por ello, mejorar la calidad de vida de la población es un proceso multidimensional y complejo (SENPLADES, 2013). Entre los derechos para mejorar la calidad de vida se incluyen el acceso al agua y a la alimentación (art. 12).

El procesamiento de los cultivos tradicionales o autóctonos como el melloco, representaría una mejora en la calidad de vida de los habitantes de nuestro país, ya que, en el Ecuador es considerado como el segundo tubérculo en importancia luego de la papa. Es parte de 
la alimentación de la población ecuatoriana de todos los estratos sociales y constituye un componente de los sistemas agrícolas de los pequeños agricultores de la sierra. Es un producto de muy buenas cualidades nutritivas. Al igual que la quinua, maíz, oca y muchos otros cultivos aborígenes forman históricamente uno de los principales alimentos del hombre andino (Abrigo, 2016).

A nivel agroindustrial, el melloco no ha sido explotado industrialmente, existiendo pocos productos que incorporen a éste tubérculo en su composición; por ejemplo, mermeladas, caramelos gomosos, conservas, hojuelas, mermeladas y harinas (Armas, 2016).

Actualmente no existen personas ni microempresas que se dediquen al procesamiento de cultivos tradicionales, por falta de conocimiento, cambio de hábitos alimenticios producidos en las comunidades, también se debe a que esta especie ha sufrido un proceso de erosión resultado de la aculturación alimenticia de los pueblos. De acuerdo a la problemática planteada resultó de gran interés proyectar alternativas micro empresariales mediante el procesamiento de tres eco tipos de ullucos proponiendo nuestra práctica y diversidad de usos y ofrecer una interesante alternativa para los campesinos y habitantes de nuestro país.

Los antecedentes expuestos generan una gran expectativa para la explotación comercial de éstos tres ecotipos (amarillo, rojo y blanco), las tecnologías que se establecieron en la presente investigación pueden ser fomentadas por organismos campesinos, empresarios privados, instituciones gubernamentales y no gubernamentales que tiendan a impulsar y promocionar los beneficios del melloco.

Para el desarrollo del presente trabajo investigativo se planteó los siguientes objetivos:

\section{Objetivo Primario:}

- Conocer el manejo de procesos agroindustriales para mejorar la calidad, aceptabilidad y prolongar el tiempo de almacenamiento y posterior consumo del melloco

\section{Objetivos secundarios:}

- Determinar los diferentes usos de los tres ecotipos de melloco aplicando un proceso artesanal.

- Establecer la aceptabilidad, costos de producción y rentabilidad de los productos obtenidos mediante el procesamiento de tres ecotipos de melloco.

- Difundir a los beneficiarios directos e indirectos, las técnicas de procesamiento.

Hipótesis: "De los tres ecotipos de melloco por lo menos un derivado nutritivo tendrá aceptación y demanda permitiendo una adecuada comercialización, además que el análisis del costo beneficio indicarán que el proyecto es factible".

Los objetivos e hipótesis de la presente investigación están relacionados directamente, ya que, se utilizarán nuevos métodos de procesamiento como mermelada, harina y hojuelas, cuyos resultados al concluir el ensayo influenciarán directamente en el incremento de sus ganancias, siendo muy beneficioso porque permitirá aumentar su valor agregado. 
Explore la Importancia del problema: El problema radica porque no existen métodos de procesamiento definidos, debido a la aculturación alimenticia y al desconocimiento. De ahí el interés por saber cuáles son los productos obtenidos mediante los procesos artesanales de los tres eco tipos de melloco.

\section{Métodos}

Se ejecutó una investigación experimental - acción - participación, valiéndonos para ello de la observación directa y la aplicación de encuestas. El método científico que se utilizó en la presente investigación fue el siguiente:

Histórico - Lógico: Se partió de la organización y análisis de la evolución histórica de los principales conceptos que aquí se tienen en cuenta (Cultivos autóctonos, procesamiento, características organolépticas) para visualizar la trayectoria real de las causas y efectos que han generado el desconocimiento de procesos agroindustriales en la comunidad.

Las técnicas que se utilizaron en la presente investigación fueron desglosadas de la siguiente manera:

La observación: Visualizó la realidad del hecho a investigar.

La encuesta: El tipo de encuestas aplicadas fueron anónimas y las preguntas se desarrollaron de forma abierta, para lo cual se les solicitó ayuda para la contestación de las preguntas que se encuentran impresas en un cuestionario (Abrigo, 2016).

En éste trabajo investigativo se utilizaron los siguientes materiales:

\section{Material de laboratorio:}

- Los análisis del porcentaje de humedad se realizaron en el laboratorio de análisis Físico Químicos de Suelos y Aguas y Alimentos del AARRR de la UNL.

\section{Material de oficina:}

- Encuestas

- Materiales de oficina

\section{Material de Procesamiento}

- Tubérculos de melloco verde, rojo y blanco

\section{Material de cocina}

- Cocina industrial, ollas, jarra, tamices, cuchillos rebanadora manual con cuchilla de acero inoxidable con regulador tipo mariposa, cucharas, recipientes, algodón

\section{Material de vidrio y fundas}

- Envases de 250 y $500 \mathrm{ml}$ para mermeladas

- Fundas de alta densidad de 250 y 500 gramos para hojuelas y harina. 


\section{Equipos}

- Despulpadora (licuadora)

- Balanza de kilogramos y de precisión

- Refractómetro

- Termómetros

\section{Aparatos para el secado, molido y sellado}

- Secador de bandeja

- Molino de martillos

- Sellador de fundas de alta densidad

\section{Sustancias químicas e ingredientes}

- Azúcar y pectina siguiente:

La metodología utilizada para la elaboración de mermeladas, harina y hojuelas fue la

\section{Elaboración de mermeladas}

Las mermeladas de melloco se realizaron en el Laboratorio de PI del AARNR de la UNL, donde se combinaron con frutos de uvilla y babaco con una relación pulpa / azúcar de 55 / 45 , hasta alcanzar los 65 grados Brix registrado en el zumo de pulpa.

\begin{tabular}{|lc|}
\hline Materia Prima & $\%$ \\
Melloco con babaco & \\
Tubérculos de melloco & 17,0 \\
Frutos de babaco & 38,5 \\
Azúcar & 45,00 \\
Pectina & 0,9 \\
Melloco con uvilla & \\
Tubérculos de melloco & 22,00 \\
Frutos de uvilla & 33,0 \\
Azúcar & 45,0 \\
Pectina & 0,9 \\
\hline
\end{tabular}

Cuadro 1. Porcentajes generales de materia prima para la elaboración de mermeladas de melloco con babaco y uvilla

Fuente y elaboración: El autor

El procedimiento para la elaboración de mermeladas de melloco con babaco y uvilla consta en el siguiente diagrama de flujo y su secuencia fotográfica. 


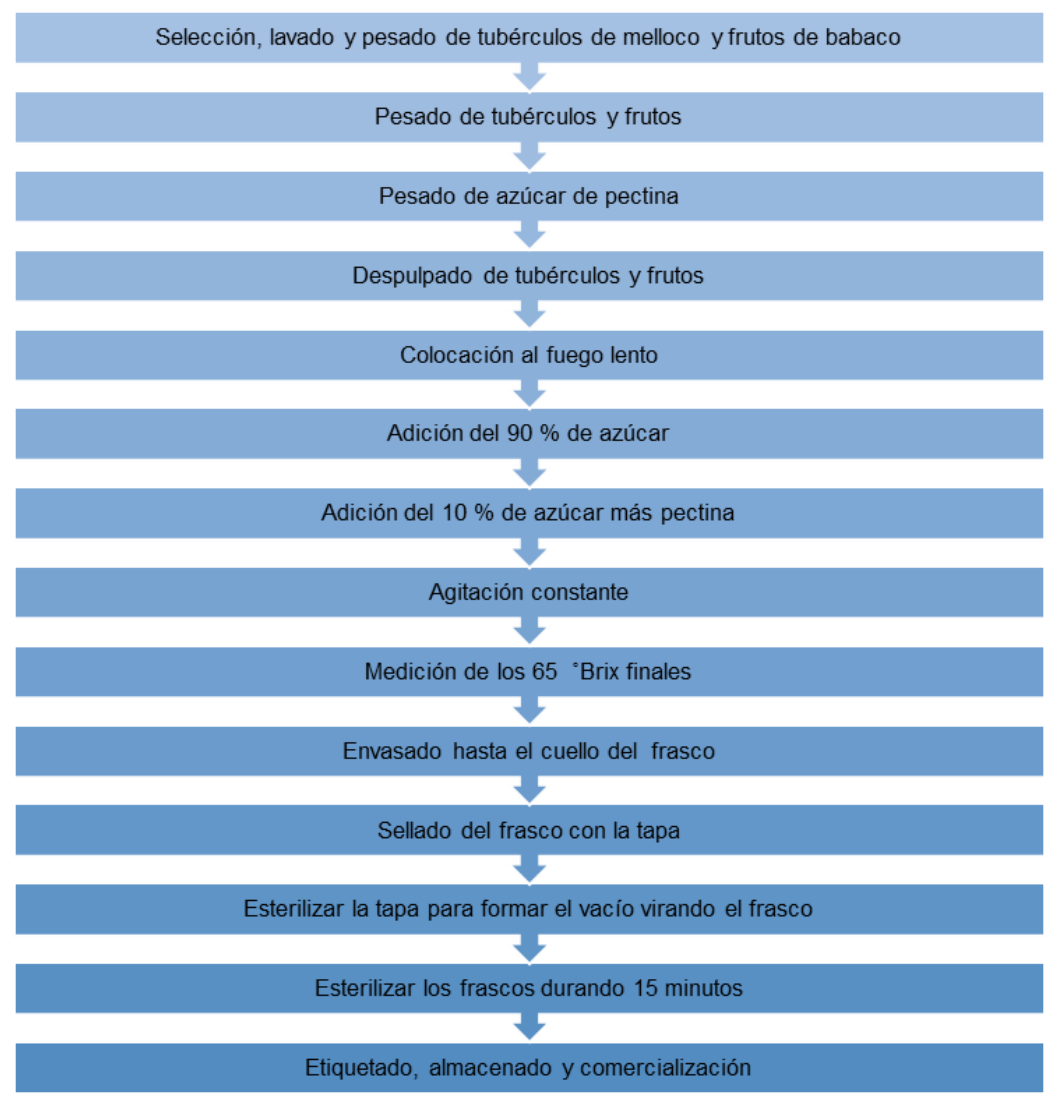

Figura 1. Diagrama de flujo para la elaboración de mermeladas de melloco con babaco y uvilla.

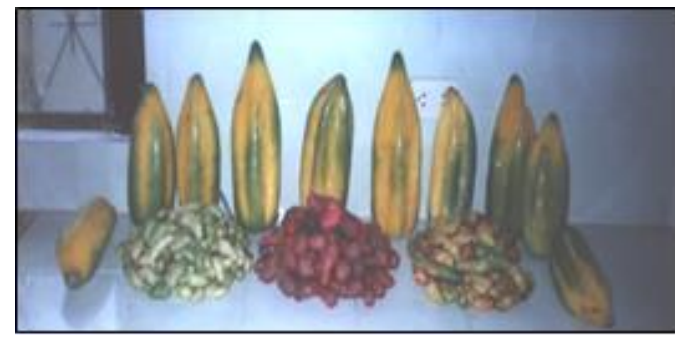

1.Selección de tubérculos de melloco y frutos de babaco

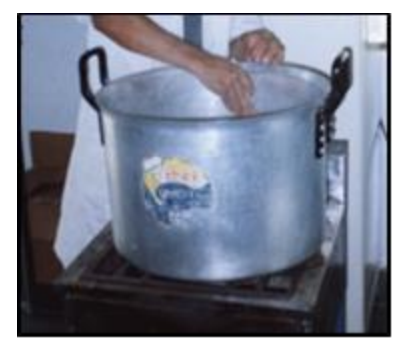

2.Mezcla de Ingredientes

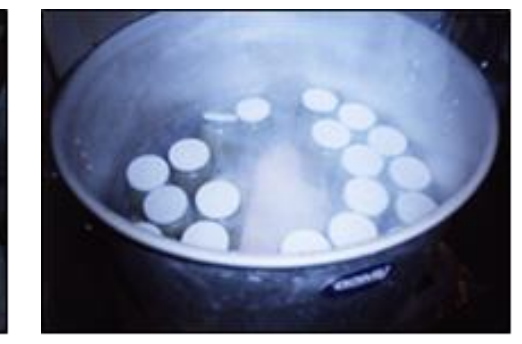

5. Esterilización

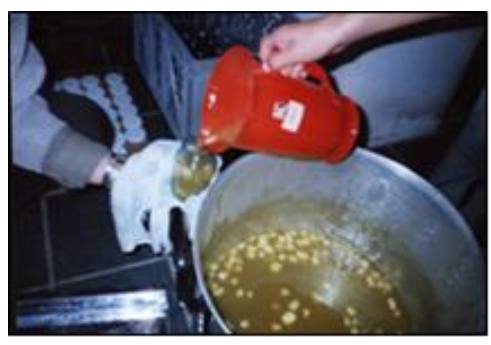

4. Envasado

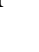




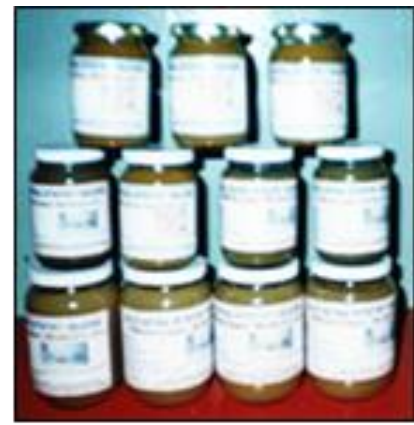

6. Etiquetado

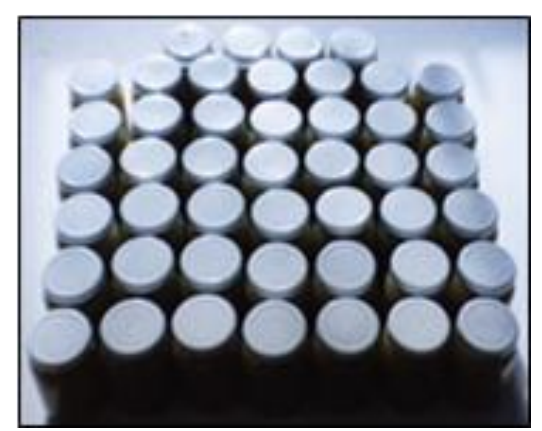

7. Almacenamiento

Figura 2. Secuencia fotográfica para la obtención de mermeladas de melloco con babaco.

\section{Análisis organolépticos de las mermeladas}

Los análisis referidos en el apartado se basan primariamente en: el olor, color y sabor, los cuales se realizaron en las diferentes exposiciones donde se exhibieron los derivados del melloco, especialmente en la Casa Abierta del AARNR, así como la Expoferia Agropecuaria, entregando como probadores a los asistentes. También se realizaron pruebas de palatabilidad a amigos, parientes utilizando el siguiente formato de la tabla 1 y 2.

\section{Elaboración de harinas}

Se siguió el siguiente procedimiento:

a) Selección de la materia prima y lavado: Se clasificaron los tubérculos de acuerdo tamaño (grande, mediano y pequeño) y al color (rojo, blanco y verde). Posteriormente se eliminó los tubérculos partidos, picados y deteriorados; seguidamente se lavaron con abundante agua para eliminar la tierra impregnada.

b) Cortado en hojuelas: El cortado se lo realizo en forma manual, con la ayuda de un rebanador manual para patatas; en donde los tubérculos fueron cortados en hojuelas de espesor uniforme.

c) Selección del espesor adecuado: Se determinó por la cantidad de producto seco obtenido frente al tiempo de secado. En el cuadro 2 se muestra las pruebas con varios espesores.

\begin{tabular}{lllll}
\hline $\begin{array}{l}\text { Ecotipos de } \\
\text { Melloco }\end{array}$ & $\begin{array}{l}\text { Espesor de la } \\
\text { Hojuela }(\mathrm{mm})\end{array}$ & $\begin{array}{l}\text { Peso de la muestra } \\
\text { húmeda }(\mathrm{g})\end{array}$ & $\begin{array}{l}\text { Peso de la muestra } \\
\text { Seca }(\mathrm{g})\end{array}$ & $\begin{array}{l}\text { Tiempo de secado } \\
\text { (horas) }\end{array}$ \\
\hline -Rojo & 6 & 2750 & $342,0^{*}$ & $20 \mathrm{~h} 20$ \\
\hline -Rojo & 4 & 2750 & 342,0 & $15 \mathrm{~h} 00$ \\
\hline -Rojo & 3 & 2750 & 342,0 & $7 \mathrm{~h} 47$ \\
\hline -Blanco & 6 & 2750 & 454,3 & $18 \mathrm{~h} 55$ \\
\hline -Blanco & 4 & 2750 & 454,3 & $8 \mathrm{~h} 40$ \\
\hline -Blanco & 3 & 2750 & 454,3 & $6 \mathrm{~h} 50$ \\
\hline -Verde & 6 & 2750 & 393,1 & $15 \mathrm{~h} 05$ \\
\hline -Verde & 4 & 2750 & 393,1 & $8 \mathrm{~h} 32$ \\
\hline -Verde & 3 & 2750 & 393,1 & $5 \mathrm{~h} 50$ \\
\hline
\end{tabular}

Cuadro 2. Espesores utilizados en las hojuelas, previos al secado a $70{ }^{\circ} \mathrm{C}$.

* Rendimientos obtenidos por cada eco tipo, varían por la cantidad de humedad que poseen. 


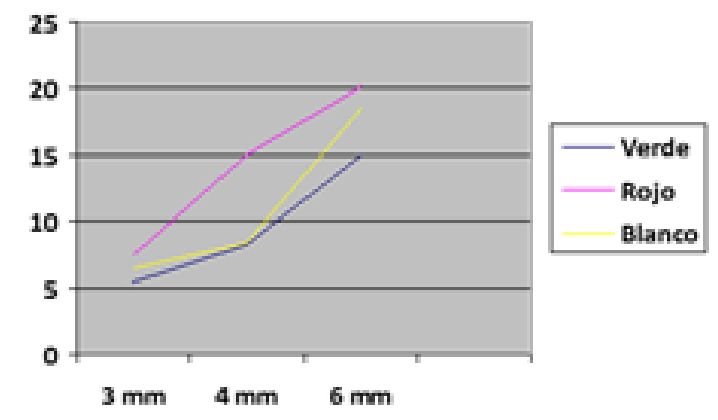

Figura 3. Curvas de deshidratación de las hojuelas

\begin{tabular}{cccc}
\hline $\begin{array}{c}\text { Materia prima } \\
\text { Ecotipos de melloco }\end{array}$ & $\begin{array}{c}\text { Materia fresca } \\
(\%)\end{array}$ & $\begin{array}{c}\text { Materia seca } \\
(\%)\end{array}$ & $\begin{array}{c}\text { Humedad* } \\
(\%)\end{array}$ \\
\hline -Rojo & 100,0 & 11,69 & 88,31 \\
-Verde & 100,0 & 13,44 & 86,56 \\
-Blanco & 100,0 & 15,53 & 84,47 \\
\hline
\end{tabular}

Cuadro 3. Porcentajes de materia fresca, seca y humedad de los tres eco tipos de melloco. *Fuente: Laboratorio de análisis físico-químico de suelos, aguas y alimentos.

d) Deshidratación o secado: Para la deshidratación de las hojuelas de melloco se utilizó un secador artesanal de latón galvanizado, cuya sección es de $50 \mathrm{~cm}$ x $50 \mathrm{~cm}$ (ancho y alto) y longitud de $65 \mathrm{~cm}$, con capacidad para dos bandejas previamente agujeradas, un pequeño ventilador que ayuda a la libre circulación del aire caliente por todo el espacio del secador.

e) Molido: Se realizó en un molino de corriente de 110 V y 0,75 HP de tres martillos, las hojuelas secas son rotas por un grupo de martillos articulados, conectados a un disco giratorio. El molino utilizado, es de eje horizontal y de un solo eje giratorio, en el que están montado tres martillos. Se utilizó una malla de $5 \mathrm{~mm}$.

f) Tamizado: Para obtener un producto con tamaño de partícula más o menos homogéneo, se utilizó un tamiz de 5 micras.

g) Envasado: El envasado se efectuó en fundas de alta densidad, ya sea de 250 ó 500 g, luego se selló y se etiqueto.

A continuación presentamos el diagrama de flujo y la sesión fotográfica para la obtención de harina de melloco.

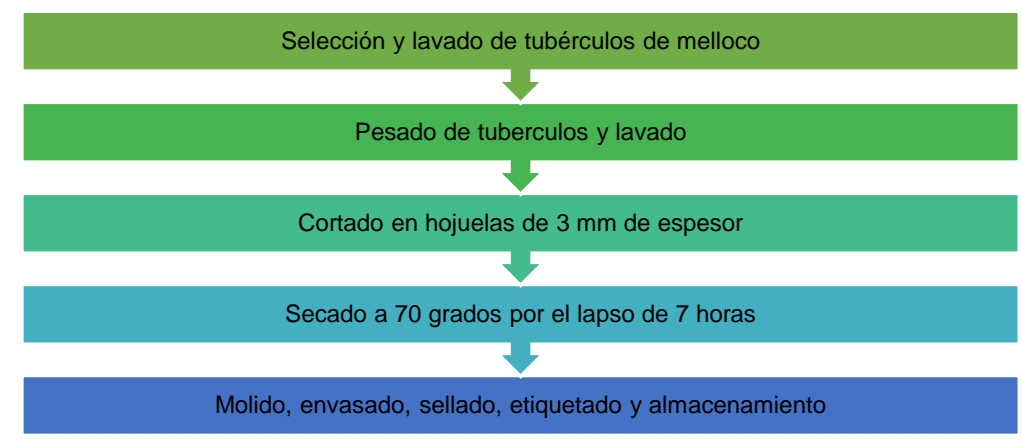

Figura 4. Diagrama de flujo para la elaboración de harina de melloco. 


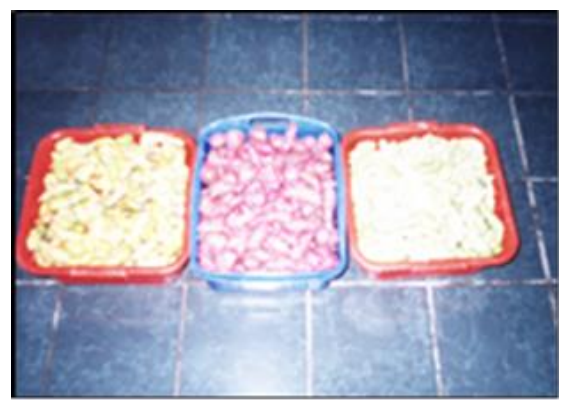

1. Selección de los ecos tipos verde, rojo y blanco

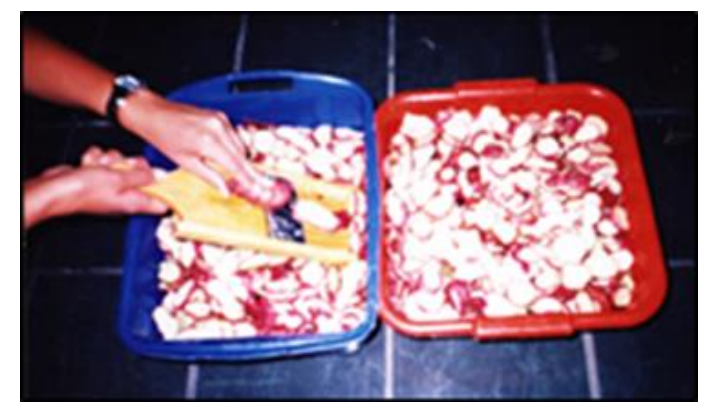

2. Cortado en hojuelas de $3 \mathrm{~mm}$ de espesor

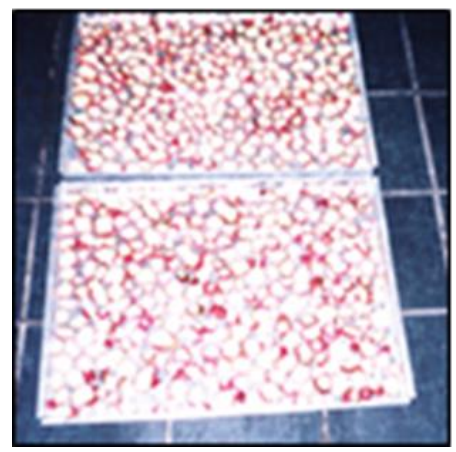

3. Colocación en bandejas previo al secado

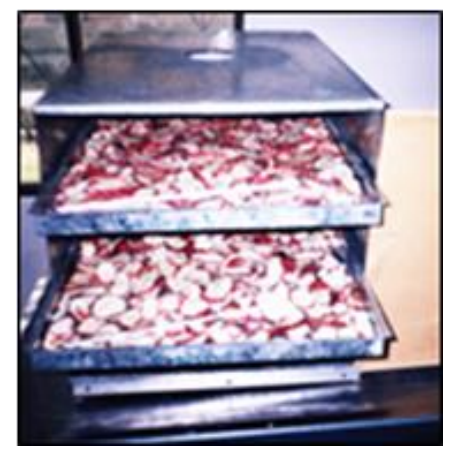

4. Secado a $70{ }^{\circ} \mathrm{C}$ por 7 horas

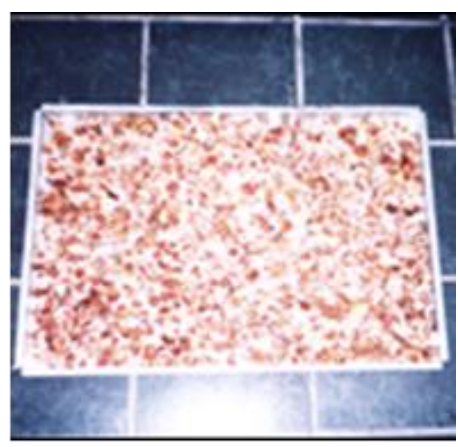

5. Melloco deshidratado

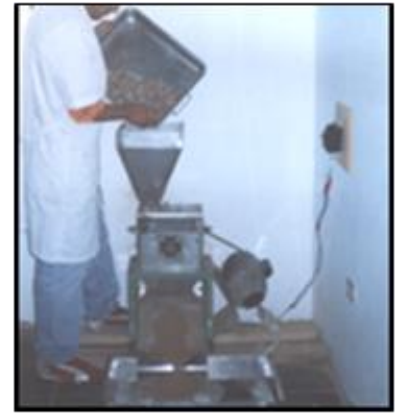

6. Molido

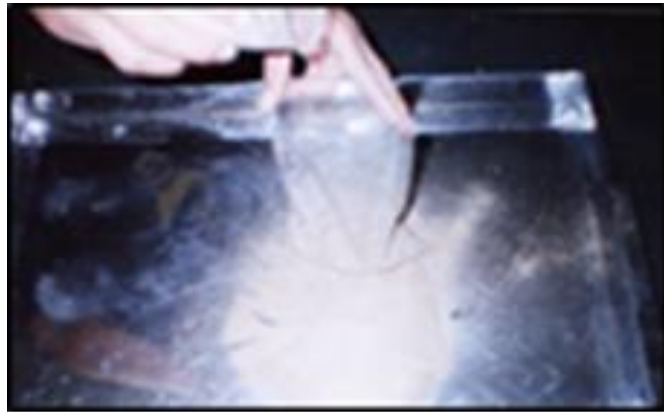

7. Envasado

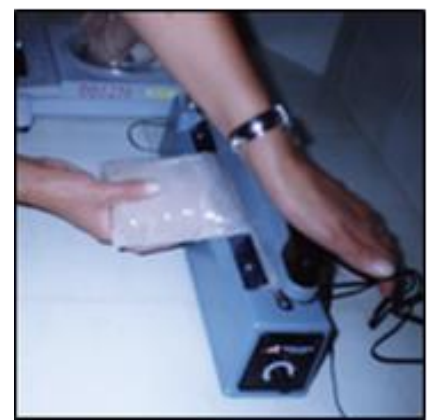

8. Sellado
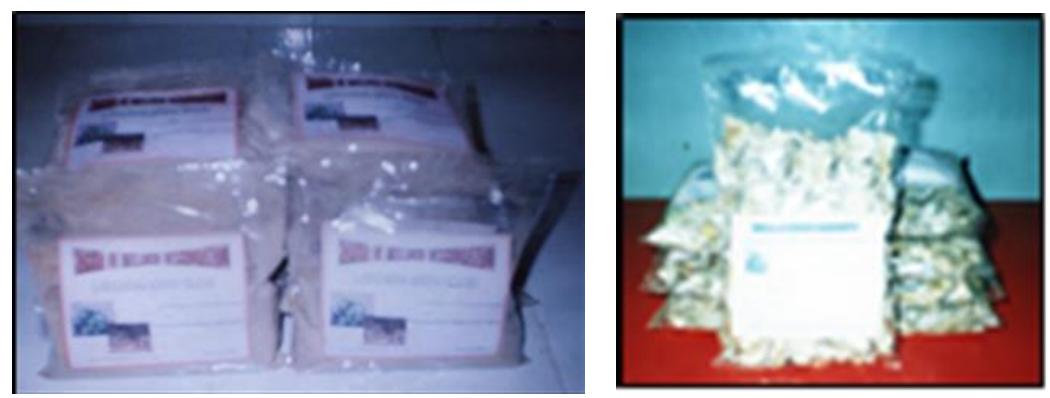

9. Etiquetado y almacenamiento de harina y hojuelas

Figura 5. Secuencia fotográfica para la obtención de harina de melloco

\section{Análisis organolépticos de la harina}


En el análisis organoléptico, se consideró el color y sabor especialmente en coladas y sopas; las pruebas de degustación se realizaron con las personas asistentes a las diferentes exposiciones donde se exhibieron los productos, especialmente en la Casa Abierta del AARNR, en Expoferia Agropecuaria, amigos y parientes, para ello se utilizó un formato de consulta de la tabla 1 y 2.

Tabla 1. Formatos para los análisis organolépticos de las mermeladas de melloco con babaco y uvilla y colada de harina de melloco con leche.

\begin{tabular}{|c|c|c|c|c|c|c|c|c|c|c|}
\hline \multirow{2}{*}{$\begin{array}{c}\text { Tipo de } \\
\text { producto }\end{array}$} & \multicolumn{3}{|c|}{ Color } & \multicolumn{3}{|c|}{ Ácido } & \multicolumn{4}{|c|}{ Textura } \\
\hline & Brillante & Poco brillante & Opaco & Dulce & Poco dulce & ácido & Fija & Poco Fija & Suave & Muy Suave \\
\hline $\begin{array}{c}\text { Mermelada d } \\
\text { melloco con } \\
\text { babaco }\end{array}$ & & & & & & & & & & \\
\hline 1. & & & & & & & & & & \\
\hline $\begin{array}{c}\text { Mermelada d } \\
\text { melloco con } \\
\text { uvilla }\end{array}$ & & & & & & & & & & \\
\hline 1. & & & & & & & & & & \\
\hline $\begin{array}{l}\text { Colada de } \\
\text { harina de } \\
\text { melloco con } \\
\text { leche }\end{array}$ & & & & & & & & & & \\
\hline & Densidad & & & & & & Firme & Suave & Espesor & Liquido \\
\hline 1. & & & & & & & & & & \\
\hline
\end{tabular}

Tabla 2. Formatos para hacer comparaciones en base a los análisis organolépticos de la sopa de harina de melloco, sopa de harina con plátano, sopa de harina de trigo y sopas de hojuelas de melloco.

\begin{tabular}{|c|c|c|c|c|c|c|c|c|}
\hline \multirow{2}{*}{$\begin{array}{c}\text { Tipo de } \\
\text { producto }\end{array}$} & \multicolumn{3}{|c|}{ Color } & \multicolumn{3}{|c|}{ Sabor } & \multicolumn{2}{|c|}{ Viscocidad } \\
\hline & Claro & Oscuro & Transparente & Muy bueno & Bueno & Malo & Liquido & Denso \\
\hline $\begin{array}{c}\text { Sopa: harina } \\
\text { de melloco }\end{array}$ & & & & & & & & \\
\hline 1. & & & & & & & & \\
\hline $\begin{array}{l}\text { Sopa: harina } \\
\text { con plátano }\end{array}$ & & & & & & & & \\
\hline 1. & & & & & & & & \\
\hline $\begin{array}{c}\text { Sopa: harina } \\
\text { de trigo }\end{array}$ & & & & & & & & \\
\hline 1. & & & & & & & & \\
\hline $\begin{array}{c}\text { Sopas: } \\
\text { hojuelas de } \\
\text { melloco }\end{array}$ & & & & & & & & \\
\hline 1. & & & & & & & & \\
\hline
\end{tabular}

\section{Determinación del rendimiento}

Se calcularon los rendimientos en porcentaje de harina que se obtuvo para cada ecotipo. Como por ejemplo: en el eco tipo blanco de melloco tenemos:

2750,0 g

Producto húmedo 454,3 g Producto seco

$6 \%$ de humedad

$$
\begin{aligned}
2750 \mathrm{~g} \longrightarrow & \begin{array}{l}
100 \\
454,3 \mathrm{~g}
\end{array} \\
& \mathrm{x} \\
& =16,52 \% \text { de harina }
\end{aligned}
$$


orden:

Para la aceptabilidad y demanda de los derivados de melloco se estableció el siguiente

1. Método: El Hipotético Deductivo, en base a la hipótesis conocida. "de los tres ecotipos de melloco por lo menos un derivado nutritivo tendrá aceptación y demanda permitiendo una adecuada comercialización por la comunidad".

2. Técnicas: Se utilizaron la observación directa, entrevistas y encuestas.

3. Población y Área Geográfica: Se tomaron datos del VI censo de población y V de vivienda del 2010 emitidos por el Instituto Nacional Ecuatoriano de Censos, la población total corresponde al área urbana y periférica de la ciudad de Loja.

4. Muestra: La muestra se estratifico al nivel de mercados y supermercados de la ciudad de Loja. Se contabilizo el número de personas de mayor concurrencia a los mercados y supermercados de la ciudad de Loja, en base a la tabla 3.

Tabla 3. Número de personas que acuden a los mercados y supermercados de la ciudad de Loja

\begin{tabular}{|c|c|c|c|c|}
\hline LUGAR & DÍA & HORA PICO & $\begin{array}{c}\text { NO DE } \\
\text { PERSONAS }\end{array}$ & $\begin{array}{l}\text { TAMAÑO DE LA MUESTRA } \\
(\mathrm{N})\end{array}$ \\
\hline \multicolumn{5}{|l|}{ Mercados } \\
\hline Gran Colombia & Domingo & $07 \mathrm{~h} 00-11 \mathrm{~h} 00$ & 450 & 50 encuestas \\
\hline Mayorista & Domingo & $07 \mathrm{~h} 00-11 \mathrm{~h} 00$ & 450 & 48 encuestas \\
\hline San Sebastián & Domingo & $08 \mathrm{~h} 00-11 \mathrm{~h} 00$ & 450 & 51 encuestas \\
\hline Las Pitas & Sábado & $07 \mathrm{~h} 00-11 \mathrm{~h} 00$ & 450 & 50 encuestas \\
\hline La Tebaida & Sábado & $07 \mathrm{~h} 00-11 \mathrm{~h} 00$ & 450 & 40 encuestas \\
\hline $\begin{array}{l}\text { Centro Comercial } \\
\text { Loja }\end{array}$ & Domingo & $08 \mathrm{~h} 00-11 \mathrm{~h} 00$ & 450 & 51 encuestas \\
\hline \multicolumn{5}{|l|}{ Supermercados } \\
\hline Comercial ROMAR & Sábado & $\begin{array}{l}09 \mathrm{H} 00- \\
12 \mathrm{H} 00\end{array}$ & 180 & 43 encuestas \\
\hline Comercial TIA & Sábado & & 170 & 40 encuestas \\
\hline MERCAMAX & Domingo & $\begin{array}{c}09 \mathrm{H} 00- \\
12 \mathrm{H} 00\end{array}$ & 100 & 36 encuestas \\
\hline SERVIPRAYSS & Domingo & $\begin{array}{c}09 \mathrm{H} 00- \\
12 \mathrm{H} 00\end{array}$ & 125 & 39 encuestas \\
\hline \multirow[t]{2}{*}{ SUPERMAXI } & Domingo & $\begin{array}{l}09 \mathrm{H} 00- \\
12 \mathrm{H} 00\end{array}$ & 350 & 49 encuestas \\
\hline & & $\begin{array}{l}09 \mathrm{H} 00- \\
12 \mathrm{H} 00\end{array}$ & & \\
\hline TOTAL & & & 3225 & 497 encuestas \\
\hline
\end{tabular}


5. Tamaño de la muestra: Se calculó en base a los datos obtenidos de la cantidad de personas que acuden a los mercados y supermercados de la ciudad de Loja, de acuerdo a la siguiente fórmula.

$$
\mathrm{N}=\frac{\mathrm{N} \cdot \mathrm{Z} \cdot \mathrm{p} \cdot \mathrm{q}}{\mathrm{Z} \cdot \mathrm{p} \cdot \mathrm{q}+(\mathrm{N}-1) \cdot \mathrm{e}}
$$

Dónde:

$\mathrm{N}=$ Población estimada

$\mathrm{Z}=$ Valor critico $(\mathrm{Z}$ al $90 \%=1,64)$

$\mathrm{p}=$ Probabilidad de tener respuestas positivas $(70 \%)$

$\mathrm{q}=$ Probabilidad de tener respuestas negativas $(30 \%)$

e $=$ Margen de error al 10\% (precisión)

$\mathrm{n}=$ Tamaño de la muestra

Los valores de p y q se tomaron a partir de un sondeo inicial, la precisión se tomó el 10\% debido a que encuestas de tipo social se acepta hasta este margen de error.

6. Encuestas: Una vez establecido el número de encuestas, se aplicó a personas que realizan compras en los mercados y supermercados de la ciudad de Loja en horas de mayor concurrencia.

Tabla 4. Modelo de Encuesta aplicada a los consumidores de mercados y supermercados de la ciudad de Loja.

\begin{tabular}{|c|c|c|c|c|c|c|c|c|c|c|}
\hline \multirow[t]{2}{*}{ Parámetros } & \multicolumn{2}{|c|}{$\begin{array}{l}\text { 1. Qué cantidad consume de } \\
\text { tubérculo de melloco }\end{array}$} & \multicolumn{2}{|c|}{$\begin{array}{c}\text { 2. Con qué frecuencia } \\
\text { consume el tubérculo de } \\
\text { melloco }\end{array}$} & \multicolumn{2}{|c|}{$\begin{array}{l}\text { 3. Consumiría de rivados de } \\
\text { melloco y por que razones }\end{array}$} & \multicolumn{2}{|c|}{$\begin{array}{c}\text { 4. Con que frecuencia } \\
\text { consumiría mermeladas de } \\
\text { melloco }\end{array}$} & \multicolumn{2}{|c|}{$\begin{array}{c}\text { 5. Con que frecuencia } \\
\text { consumiría harina de } \\
\text { melloco }\end{array}$} \\
\hline & Encuestas & $\%$ & Encuestas & $\%$ & Encuestas & $\%$ & Encuestas & $\%$ & Encuestas & $\%$ \\
\hline \multicolumn{11}{|l|}{$1-2$ libras } \\
\hline \multicolumn{11}{|l|}{$3-5$ libras } \\
\hline \multicolumn{11}{|l|}{$>6$ libras } \\
\hline \multicolumn{11}{|l|}{$1-2$ kilos } \\
\hline \multicolumn{11}{|l|}{$3-5$ kilos } \\
\hline \multicolumn{11}{|l|}{$>6$ kilos } \\
\hline \multicolumn{11}{|l|}{ No consumen } \\
\hline \multicolumn{11}{|l|}{ Diariamente } \\
\hline \multicolumn{11}{|l|}{ Semanalmente } \\
\hline \multicolumn{11}{|l|}{ Mensualmente } \\
\hline \multicolumn{11}{|l|}{ No consume } \\
\hline \multicolumn{11}{|l|}{ Mermelada } \\
\hline \multicolumn{11}{|l|}{ Harina } \\
\hline \multicolumn{11}{|l|}{ No consume } \\
\hline \multicolumn{11}{|l|}{ Valor nutritivo } \\
\hline \multicolumn{11}{|l|}{ Valor medicinal } \\
\hline \multicolumn{11}{|l|}{\begin{tabular}{|c|}
$\begin{array}{c}\text { Por conocer su } \\
\text { sabor }\end{array}$ \\
\end{tabular}} \\
\hline \multicolumn{11}{|l|}{\begin{tabular}{|l|} 
Producto nuevo \\
\end{tabular}} \\
\hline \multicolumn{11}{|l|}{ Otras } \\
\hline Total & 497 & 100 & 497 & 100 & 497 & 100 & 497 & 100 & 497 & 100 \\
\hline
\end{tabular}

Tabulación de datos: Se realizó mediante tablas y diagramas estadísticos que fueron debidamente interpretados.

\section{Análisis de la demanda}


Para determinar la demanda se basó en los resultados obtenidos de las preguntas 1, 2, 3 y 4 de las encuestas sobre la cantidad y frecuencia de consumo del producto y derivados (Tabla 4), estos datos nos sirvieron como base la demanda futura y potencial.

Examinados los datos se determinó la cantidad de consumo semanal y mensual en $\mathrm{Kg}$ de tubérculo fresco; de acuerdo al número de familias que consumen mensualmente se estableció un promedio de consumo, proyectándose la demanda futura hasta los cinco años.

Para determinar la demanda futura del número de habitantes del sector urbano de la ciudad de Loja, se tomó los datos actualizados por el INEC y los resultados obtenidos de la encuesta emiten un promedio de 5,1 miembros por familia, con lo que se determinó el número de familias del sector urbano de la ciudad de Loja. Para la proyección de la demanda futura se realizó utilizando los siguientes formulas:

Proyección Urbana $=$ P1 $(1+\mathrm{i})$

Demanda Futura= D1 $(1+\mathrm{i})$

Tasa de crecimiento poblacional $=2,65 \%$

\section{Análisis de la comercialización}

Para el análisis de la comercialización de los derivados, se diseñaron dos canales óptimos, tratando de eliminar la mayor cantidad de intermediarios. Y para la presentación del producto final se eligió un tipo de envase con etiqueta que contiene ciertas características como: ingredientes, contenido del envase y la envoltura.

\section{Resultados}

\section{Determinar los diferentes usos de los tres ecotipos de melloco aplicando un proceso artesanal}

Los resultados de la presente investigación fueron muy satisfactorios, debido a que se lograron obtener productos derivados del melloco mediante un proceso casero sencillo (ver apartado anterior) como son las mermeladas de melloco con frutos de babaco y uvilla en una relación de 55 a 45, harina de melloco propicia para la elaboración de coladas y hojuelas de melloco para producir sopas.

\section{Establecer la aceptabilidad, costos de producción y rentabilidad de los productos obtenidos mediante el procesamiento de tres ecotipos de melloco.}

Se procedió a calcular los costos de producción por cada cincuenta unidades, en el caso de las mermeladas; así como en presentaciones de 1 kilo de harina y de hojuelas. Se tomó también en cuenta la depresión anual de los materiales y aparatos utilizados en las elaboraciones de estos derivados, lo que se detalla a continuación.

\begin{tabular}{lll}
\hline Descripción & $\begin{array}{l}\text { Valor de } \\
\text { adquisición \$ }\end{array}$ & Porcentajes de Usos (\%)* \\
\hline
\end{tabular}




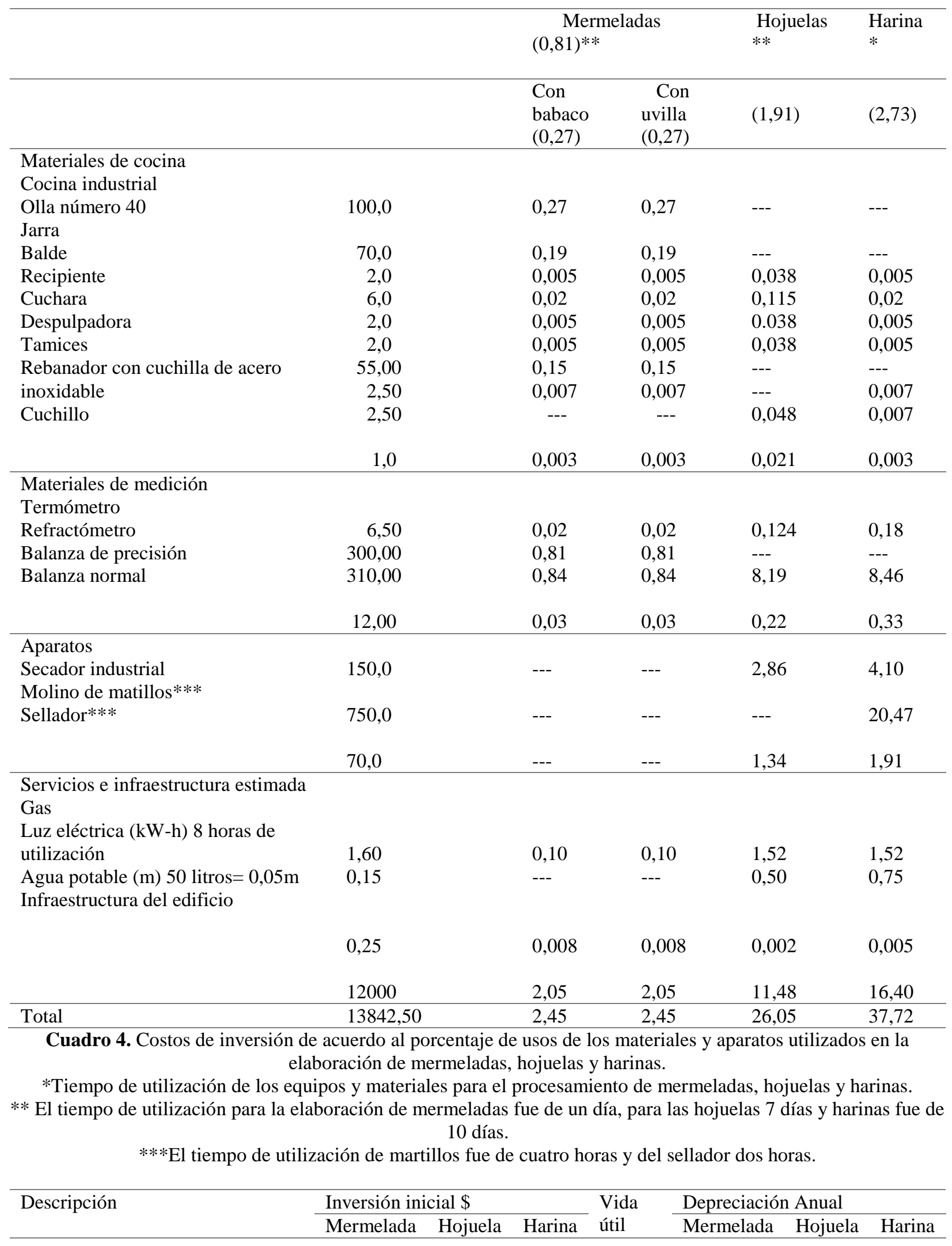




\begin{tabular}{|c|c|c|c|c|c|c|c|}
\hline $\begin{array}{l}\text { Materiales de cocina } \\
\text { Cocina industrial }\end{array}$ & & & & & & & \\
\hline Olla número 40 & 0,27 & --- & --- & 5 & 0,049 & --- & --- \\
\hline Jarra & 0,19 & --- & --- & 5 & 0,034 & --- & --- \\
\hline Balde & 0,005 & 0,038 & 0,005 & 2 & 0,002 & 0,017 & 0,002 \\
\hline Recipiente & 0,02 & 0,115 & 0,020 & 2 & 0,001 & 0,052 & 0,001 \\
\hline Cuchara & 0,005 & 0,038 & 0,005 & 2 & 0,002 & 0,017 & 0,002 \\
\hline Despulpadora & 0,005 & 0,038 & 0,005 & 2 & 0,002 & --- & 0,002 \\
\hline Tamices & 0,15 & --- & --- & 15 & 0,008 & --- & --- \\
\hline Rebanador con cuchilla de acero & 0,007 & --- & 0,007 & 2 & 0,003 & 0,003 & 0,003 \\
\hline Cuchillo & --- & 0,048 & 0,007 & 2 & --- & 0,003 & 0,003 \\
\hline & 0,003 & 0,021 & 0,003 & 2 & 0,001 & 0,001 & 0,001 \\
\hline $\begin{array}{l}\text { Materiales de medición } \\
\text { Termómetro }\end{array}$ & & & & & & & \\
\hline Refractómetro & 0,02 & 0,124 & 0,02 & 15 & 0,003 & 0,006 & 0,003 \\
\hline Balanza de precisión & 0,81 & --- & --- & 15 & --- & --- & 0,043 \\
\hline Balanza normal & 0,84 & 8,19 & 0,84 & 20 & 0,034 & 0,32 & 0,034 \\
\hline & 0,03 & 0,22 & 0,03 & 5 & 0,005 & 0,04 & 0,005 \\
\hline Aparatos & & & & & & & \\
\hline Secador industrial* & --- & 2,86 & 4,10 & 15 & --- & 0,152 & 0,22 \\
\hline Molino de matillos* & --- & --- & 20,47 & 15 & --- & --- & 1,092 \\
\hline SCriation & --- & 1,34 & 1,91 & 5 & --- & 0,241 & 0,35 \\
\hline $\begin{array}{l}\text { Servicios e infraestructura } \\
\text { estimada } \\
\text { Gas }\end{array}$ & & & & & & & \\
\hline Luz eléctrica (kW-h) 8 horas de & 0,10 & 1,52 & 1,52 & --- & 0,10 & 1,52 & 1,52 \\
\hline utilización & --- & 0,50 & 0,75 & --- & --- & 0,50 & 0,75 \\
\hline & 0,008 & 0,002 & 0,005 & --- & 0,008 & 0,002 & 0,005 \\
\hline & 2,05 & 11,48 & 16,40 & 30 & 0.05 & 0,306 & 0,437 \\
\hline Total & & & & & 0,351 & 3,238 & 4,688 \\
\hline Mermeladas elaboradas & & & & & 160,0 & & \\
\hline Harina prod. $(\mathrm{Kg})$ & & & & & & & \\
\hline Hojuelas prod. $(\mathrm{Kg})$ & & & & & & 25,00 & \\
\hline
\end{tabular}

Cuadro 5. Depreciación anual de los materiales y aparatos utilizados en la elaboración de mermeladas, hojuelas y harinas.

*Uso exclusivo para la elaboración de harinas

**Uso exclusivo para la elaboración de mermeladas

\section{Costos de producción de las mermeladas de melloco con babaco y uvilla, hojuelas y harina de melloco}

Tabla 5. Costos de producción de mermeladas de melloco con babaco y uvilla, hojuelas y

harina de melloco.

\begin{tabular}{|c|c|c|c|c|}
\hline Descripción & Mermeladas & 0 unidades) & Hojuelas (1 kilo) & Harina (1 kilo) \\
\hline & Con Babaco & Con uvilla & & \\
\hline Costos variables & 38,81 & 41,36 & 4,50 & 4,50 \\
\hline
\end{tabular}




\begin{tabular}{lllll}
\hline Costos fijos & 0,11 & 0,11 & 0,15 & 0,19 \\
\hline Costos totales & 46,71 & 49,75 & 5,58 & 5,62 \\
\hline
\end{tabular}

Tabla 6. Costos de producción de las mermeladas de melloco con uvilla.

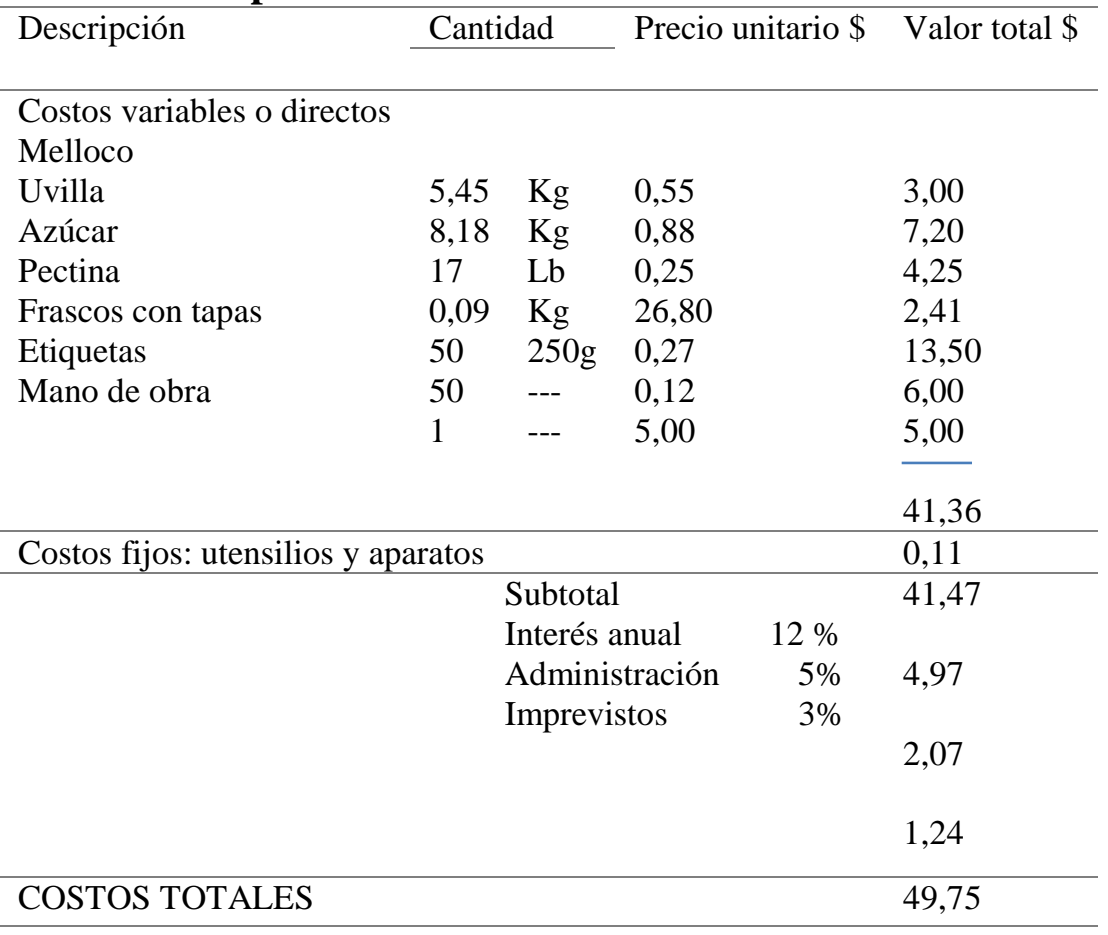

Tabla 7. Costos totales por año para la elaboración de mermeladas de melloco con uvilla.

\begin{tabular}{lrcc}
\hline Rubros & & \multicolumn{2}{c}{ Unidades elaboradas } \\
\cline { 3 - 4 } & & Año 1:41 600 & Año 2: 41600 \\
\hline Costos variables & & 34411,52 & 34411,52 \\
Costos fijos & 292,03 & 292,03 \\
Interés anual & $5 \%$ & 4164,42 & $--*^{*}$ \\
Administración & $3 \%$ & 1735,17 & 1735,17 \\
Imprevistos & $5 \%$ & 1735,17 & 1735,17 \\
Publicidad y propaganda & $5 \%$ & 1735,17 & 1735,17 \\
Transporte embalaje & & 45114,58 & 40950,16 \\
\hline Costos totales \$ & &
\end{tabular}

*A partir del segundo año, la circulación del capital es inmediata, es por ello que no se suma el valor de los intereses.

Tabla 8. Beneficios totales por año de la comercialización de mermeladas de melloco con uvilla.

\begin{tabular}{|c|c|c|c|c|c|}
\hline \multirow[t]{2}{*}{ Años } & \multicolumn{2}{|l|}{ Unidad producidas } & \multirow[t]{2}{*}{ Costo unitario \$ } & \multirow{2}{*}{$\begin{array}{l}\text { Precio de ventas } \\
\$\end{array}$} & \multirow[t]{2}{*}{ Valor total \$ } \\
\hline & Producción total* & Unidades vendidas & & & \\
\hline 1 & $41600 *$ & 37440 & 0,99 & 1,15 & 43056,00 \\
\hline 2 & $41600 * *$ & 40768 & 0,99 & 1,15 & 46883,20 \\
\hline
\end{tabular}

*El $10 \%$ de unidades elaboradas se destina a promociones y probadores.

**El $2 \%$ representa las perdidas por manipulación.

\section{Harina de melloco (eco tipo verde)}


Tabla 9. Costos de producción para la elaboración de un kilo de harina de melloco

Descripción Cantidad Precio unitario \$ Valor total \$

Tabla 10. Costos totales por año para la elaboración de harina de melloco

\begin{tabular}{lrcc}
\hline Rubros & \multicolumn{2}{c}{ Kilos producidos } \\
\cline { 3 - 4 } & & Año 1: 650 & Año 2: 650 \\
\hline Costos variables & 2925,0 & 2925,0 \\
Costos fijos & & 123,5 & 123,5 \\
Interés anual & $12 \%$ & 365,82 & $--* *$ \\
Administración & $5 \%$ & 152,42 & 152,42 \\
Imprevistos & $3 \%$ & 191,45 & 191,45 \\
Publicidad y propaganda & $5 \%$ & 152,42 & 152,42 \\
Transporte embalaje & $5 \%$ & 152,42 & 152,42 \\
Costos totales \$ & & 3697,21 & 3331,39 \\
\hline
\end{tabular}

*A partir del segundo año, la circulación del capital es inmediata, es por ello que no se suma el valor de los intereses.

Tabla 11. Beneficios totales por año de la comercialización de harina de melloco.

\begin{tabular}{llllll}
\hline \multirow{2}{*}{ Año } & Kilos producidos & \multicolumn{2}{c}{ Costo unitario \$ } & Precio de venta \$ & Valor total \$ \\
\cline { 2 - 5 } & Producción total & Kilos vendidos & \\
\hline 1 & $650 *$ & 585,0 & 5,62 & 6,15 & 3597,75 \\
\hline 2 & $650 *$ & 637,0 & 5,62 & 6,15 & 3917,55 \\
\hline \multicolumn{5}{c}{$*$ El 10 \% de kilos producidos se destina a promociones y probadores. } \\
\multicolumn{5}{c}{$* *$ El 2 \% representa las perdidas por manipulación. }
\end{tabular}

\section{Análisis organolépticos}

Tabla 12. Análisis organolépticos de la mermelada de melloco con babaco y uvilla, hojuelas y harina de melloco

\begin{tabular}{llcll}
\hline \multirow{2}{*}{$\begin{array}{l}\text { Características } \\
\text { organolépticas }\end{array}$} & \multicolumn{2}{c}{ Mermeladas de melloco } & Hojuelas & Harina \\
\hline Color & Con babaco & Con uvilla & & \\
& Amarillo & Amarillo & Café claro con bordes & Café claro \\
& Oscuro & Brillante & rojizos & \\
& &
\end{tabular}




\begin{tabular}{lllll}
\hline Sabor & $\begin{array}{l}\text { Dulce } \\
\text { Semiacida }\end{array}$ & $\begin{array}{l}\text { Dulce } \\
\text { semiacida }\end{array}$ & Característico & Característico \\
Textura & Poco firme & Firme & Dura & Poco fina \\
Clasificación & Muy bueno & Bueno & Bueno & muy bueno \\
\hline
\end{tabular}

\section{Análisis financiero}

\begin{tabular}{|c|c|c|c|c|}
\hline \multirow{2}{*}{$\begin{array}{l}\text { Características } \\
\text { organolépticas }\end{array}$} & \multicolumn{2}{|c|}{ Mermeladas de melloco } & \multirow[t]{2}{*}{ Hojuelas } & \multirow[t]{2}{*}{ Harina } \\
\hline & Con babaco & Con uvilla & & \\
\hline TIR\% & 31,33 & 86,67 & 193,48 & 531,42 \\
\hline VAN $12 \%$ & 1905,42 & 14251,91 & 1029,16 & 1500,81 \\
\hline REL.B/C 12 \& & 1,01 & 1,09 & 1,05 & 1,56 \\
\hline PE AÑO 1: \$ & 291,86 & 254,11 & 120,96 & 1,12 \\
\hline PE AÑO 2: \$ & 291,86 & 254,11 & 12,96 & 107,24 \\
\hline TRC & 0,11 & 0,46 & 1,06 & 107,24 \\
\hline PR & $\begin{array}{l}\text { Un mes y } 9 \\
\text { días }\end{array}$ & $\begin{array}{l}5 \text { meces y } 17 \\
\text { días }\end{array}$ & $\begin{array}{l}\text { Un año y } 22 \\
\text { días }\end{array}$ & $\begin{array}{l}\text { Un año, } 1 \text { mes y } 17 \\
\text { días }\end{array}$ \\
\hline
\end{tabular}

\section{Formulaciones para las hojuelas}

Para sopas: se elaboró sopas, empleando como componentes solo las hojuelas, a más de los condimentos y quesillo, de tal manera que puedan ser comestibles.

Los catadores analizaron los siguientes aspectos: color, sabor. Para verificar los resultados se repitió la prueba de otros ingredientes (papa, plátano, zanahoria, carne y pescado) a más de las hojuelas, pues lo agregado aumenta el espesor, ya que al estar en contacto con el agua se rehidratan fácilmente confirmándose los resultados.

\section{Formulación para la harina}

Para las coladas: se realizó comparaciones con harinas de trigo y plátano, utilizando una cantidad apreciable de cada una de ellas (tres cucharadas) para elaborar coladas, empleando como componentes la harina y leche, a más de los condimentos, de tal manera que puedan ser ingeribles. Los probadores analizaron los siguientes aspectos: color, sabor, viscosidad (espesamiento), obteniéndose en orden de preferencia los siguientes resultados:

Color: melloco (Perla), plátano (gris), trigo (crema)

Sabor: melloco (muy bueno), plátano (bueno), trigo (bueno)

Viscosidad: melloco (poco espesa), plátano (espesa), trigo (espesa)

Para sopas: se realizó comparaciones con harinas de trigo y plátano, utilizando una cantidad apreciable de cada una de ellas para elaborar sopas, (6 cucharadas de cada una para tres personas), empleando como componentes solo la harina, a más de los condimentos y quesillo, de tal manera que puedan ser comestibles. 
Los catadores analizaron los siguientes aspectos: color, sabor, viscosidad (espesamiento), obteniéndose los siguientes resultados:

Color: melloco (café oscuro), plátano (gris), trigo (crema)

Sabor: melloco (muy bueno), plátano (bueno), trigo (bueno)

Viscosidad: melloco (poco espesa), plátano (espesa), trigo (espesa)

\section{Análisis de la demanda}

Tabla 14. Consumo mensual de tubérculos de melloco fresco y procesado

Tipo de producto Número de familias que consumen Demanda actual $(\mathrm{kg})$

\begin{tabular}{llllll} 
& Semanal & mensual & $\%$ & Semanal & mensual \\
\hline Tubérculo fresco & 313 & 1252 & 62,97 & 51,0 & 104,0 \\
\hline Mermeladas & 161 & 644 & 32,39 & 59,3 & 237,2 \\
\hline Harina & 287 & 1148 & 57,74 & 313,3 & 1254,0 \\
\hline Total & 761 & 3044 & 51,03 & 423,3 & 1695,2 \\
\hline
\end{tabular}

Tabla 15. Demanda actual y su proyección hasta el quinto año de consumo de melloco.

Año Población urbana* Número de familias Demanda futura Superficie cultivada Ha

\begin{tabular}{llcccc}
\cline { 3 - 4 } & Total & Consumen** & \\
\hline 2010 & 180617 & 35415 & 18072 & 92170 & 5,77 \\
2011 & 185403 & 36353 & 18550 & 94612 & 5,92 \\
2012 & 190316 & 37316 & 19041 & 97119 & 6,07 \\
2013 & 195359 & 38305 & 19546 & 99692 & 6,24 \\
2014 & 200536 & 39320 & 20063 & 102334 & 6,40 \\
2015 & 205850 & 40362 & 20595 & 105046 & 6,57 \\
2016 & 211305 & 41431 & 21141 & 107829 & 6,75 \\
\hline
\end{tabular}

*Consumen el 51\% de la población con un promedio de 5,1 kg/familia. El rendimiento anual $15949,80 \mathrm{~kg} / \mathrm{ha}$ se dio en el tratamiento A1B1 (Abrigo, 2016).

\section{Canales de Comercialización}

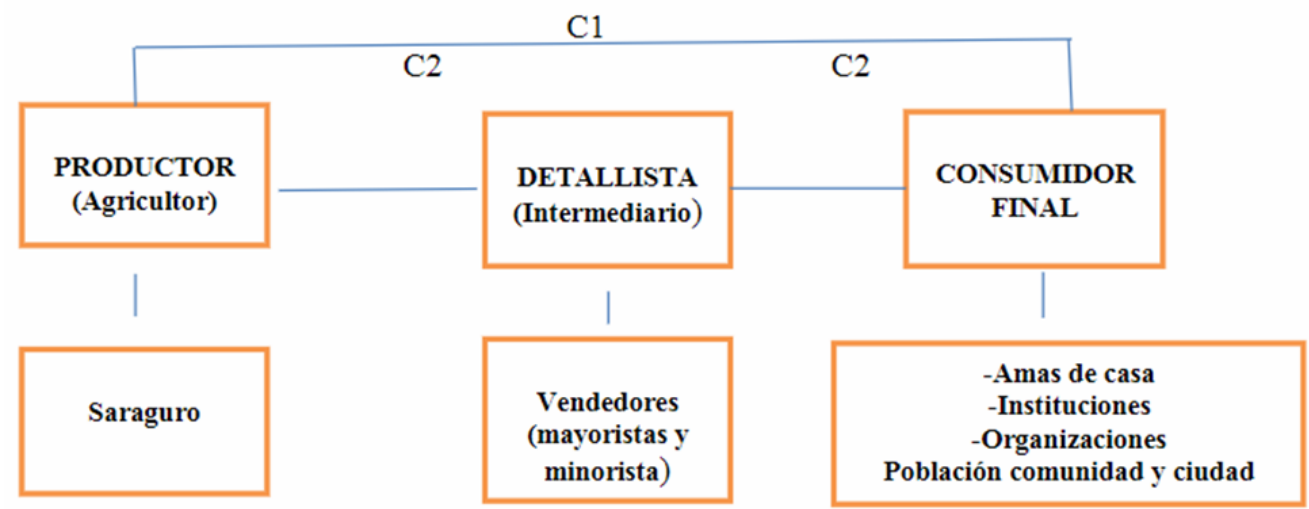

Figura 6. Flujo de los derivados del melloco desde el productor hasta el consumidor final. Publicidad y promoción final de ventas. 
Tabla 16. Eventos de publicidad, promoción y ventas de los derivados del melloco.

\begin{tabular}{|c|c|c|c|}
\hline $\begin{array}{c}\text { Evento } \\
\text { Realizado }\end{array}$ & Lugar & Fecha & Resultados \\
\hline Casa abierta & AARNR & $25 / 05 / 16$ & $\begin{array}{l}\text {-Gran aceptabilidad por parte de los asistentes a los } \\
\text { derivados. } \\
\text {-Probadores y venta de derivados. } \\
\text {-Difusión por parte del CERACYT. } \\
\text {-Interés por parte de los asistentes sobre el cultivo y sus } \\
\text { derivados, así como una promoción y adecuada propaganda. }\end{array}$ \\
\hline & & & $\begin{array}{l}\text {-Gran aceptabilidad por parte de los asistentes a los } \\
\text { derivados. }\end{array}$ \\
\hline $\begin{array}{l}\text { Feria } \\
\text { agropecuaria }\end{array}$ & $\begin{array}{l}\text { Complejo Ferial de } \\
\text { la ciudad de Loja }\end{array}$ & $\begin{array}{l}(03-17- \\
16)\end{array}$ & $\begin{array}{l}\text {-Presencia de los medios de comunicación como: radio, } \\
\text { prensa y televisión. También se entregaron a probadores y } \\
\text { venta de derivados. }\end{array}$ \\
\hline
\end{tabular}

Difundir a los beneficiarios directos e indirectos, las técnicas de procesamiento.

La socialización de los resultados del proyecto se realizó en dos sitios: El primero en la Casa Abierta organizada por el Área Agropecuaria y de RNR de la UNL, donde asistieron 150 personas de diferentes organismos, entre estudiantes, profesores y empleados públicos y privados. El segundo se efectuó en la Feria Agropecuaria organizada por el Consejo Provincial, asistiendo 1300 personas. Se pudo observar en ambos casos, el gran interés de instituciones locales y nacionales, personas particulares en fomentar el cultivo a nivel microempresarial.

\section{Discusión}

Para la elaboración de los derivados de melloco es preciso manejar la depresión anual de los aparatos y materiales correspondientes a los costos fijos utilizados en el proceso debido a que incurren en el precio unitario final, sus costos disminuyen a una mayor producción; además la venta a grandes volúmenes generan mayor utilidad, aunque este margen sea pequeño.

La producción de mermeladas de melloco con babaco se consideró directamente la relación pulpa/azúcar de 55/45 (el 70\% equivale y el 30\% a melloco, representando el 55\% de pulpa) con el 0,9\% de pectina presentando aceptables características organolépticas; en cambio, la producción de mermelada de melloco con uvilla, se consideró la misma relación 55/45, pero difiere solamente en el porcentaje de pulpa, en donde el contenido de uvilla fue de $60 \%$ y melloco $40 \%$, logrando con la adiciona de pectina al 0,9\% una buena consistencia, cabe señalar que el costo unitario sube significativamente en relación a las elaboradas con babaco y a los productos de la competencia, debido a que existe un mayor costo por kilo.

Los análisis financieros de la mermelada de melloco con babaco, indican que la TIR es $31,33 \%$ en cambio la relación $\mathrm{B} / \mathrm{C}$ es de 1,01 lo que determina que la relación $\mathrm{B} / \mathrm{C}$ es baja pero la rentabilidad es altamente significativa en relación a la TIR por la velocidad de rotación del capital, por unidad elaborada la utilidad es mínima pero se trabaja reutilizando el mismo capital; además el producto está dispuesto a la comercialización a las cuatro horas de su elaboración, la venta en grandes volúmenes pueden mejorar su rentabilidad unitaria. De igual forma sucede con las mermeladas de melloco con uvilla, la TIR tiene un valor alto del 86,67\%. 
La cantidad del producto deshidratado se determinó en función al tiempo y de acuerdo a una humedad final preestablecida del 6\%, cuyos rendimientos difieren uno del otro por la cantidad de humedad que posee cada ecotipo. Observándose que de los análisis obtenidos se desprende que al obtener harinas hemos eliminado un gran porcentaje de humedad que es del $84,47 \%$ para el ecotipo blanco, $88,31 \%$ ecotipo rojo y $86,56 \%$ para el ecotipo verde.

Los análisis financieros de la harina de melloco, indican que la TIR es de 531,42\%, en cambio la relación $\mathrm{B} / \mathrm{C}$ es de 1,12 lo que determina que la relación B/C es aceptable, pero la rentabilidad es altamente significativa en relación a la TIR por la velocidad de rotación del capital, por kilo elaborado la utilidad es tolerable pero se trabaja utilizando el mismo capital; además el producto está dispuesto a la comercialización a las siete horas de su elaboración, la venta en grandes volúmenes pueden mejorar su rentabilidad unitaria. De la misma manera ocurre con los análisis financieros obtenidos para las hojuelas, la TIR tiene un valor alto del 193,48\%, no obstante la relación $\mathrm{B} / \mathrm{C}$ del 1,05 es baja, pero la rentabilidad es alta por la rapidez de rotación del capital.

Dentro de la investigación de la aceptabilidad y demanda de los productos basados inicialmente en los datos actuales del INEC, se estableció que en la ciudad de Loja existen 40 322 familias, de las cuales se tomó una muestra representativa para la aplicación de las encuestas, estratificando en mercados y supermercados de la ciudad.

En lo que representa al conocimiento de los tubérculos de melloco, el 96,78\% de los encuestados si conocen, de los cuales el 42,25\% sabe de la procedencia y el 33,80\% conocen sobre las bondades nutricionales y medicinales de este tubérculo; además se estableció que el $90,13 \%$ de los encuestados tiene gustos y preferencias por los derivados de los tubérculos como mermeladas y harinas, especialmente están interesados por conocer el valor nutritivo y medicinal, por su sabor y por ser un producto nuevo. Aseverándose que están dispuestos a consumirlo en estas formas, siempre y cuando los precios no sean elevados, teniendo una buena higiene y adecuada presentación.

En cuanto a la frecuencia de consumo del 45 al $65 \%$ de los encuestados manifestaron que tanto los frutos y derivados los consumirán semanalmente, estableciéndose que el 47,68\% consumirán mermeladas de melloco y el 62,97 \% consumirán harina; estos datos sirvieron para realizar proyecciones de la demanda potencial.

En lo que se refiere al precio de venta, el 42,92\% de los encuestados manifestaron que el kilo lo vendían a $\$ 0,66$, de los cuales el $46,51 \%$ obtenían una utilidad de $\$ 0,15$. La variación de precios no se llegó a estabilizar en todo el año, debido a diferentes circunstancias como: la escasez, sobre demanda y a las paralizaciones que se produjeron de las vías, especialmente en el centro del país lo que ha repercutido en el abastecimiento del producto a la ciudad, influyendo en la variación de los precios.

En cuanto a la existencia en Loja de una empresa procesadora y comercializadora de mermeladas y harina de melloco, el $100 \%$ de los encuestados manifestaron que si apoyarían, de los cuales el 60,46\% lo harían por su valor nutritivo. Este interés se ve reflejado principalmente 
por el valor agredo que se le va a dar al producto, ya que existirán nuevas formas de consumo que no se las conocía actualmente.

Para determinar la demanda se tomaron datos de las tablas 7 y 8 sobre la cantidad y frecuencia de consumo de los tubérculos y derivados de melloco, lo que convierte estos datos en el consumo potencial de la cantidad de tubérculo fresco, derivándose que para compensar la demanda actual se necesitan 6,75 ha de producción de melloco solamente para satisfacer los requerimientos de las familias de la ciudad de Loja.

Analizando la comercialización, se estableció que existen dos canales adecuados para el flujo del producto y sus derivados; el primero $\mathrm{C} 1$ corresponde al flujo entre el productor y el consumidor, realizándose en forma directa a través de los pequeños productores localizados alrededor de las grandes ciudades quienes se encargan de vender sus productos en los mercados minoristas, en las ferias libres, con la venta directa en instituciones mediante exposiciones, en diferentes eventos organizado por instituciones de desarrollo de la localidad y la venta de puerta a puerta, obteniéndose un margen de utilidad mayor lo que beneficia al productor, pero resulta un bajo volumen de ventas y riesgos de daños de los productos por su manipulación. El Canal C2, corresponde al flujo entre el productor y el consumidor a través de un intermediario.

Para la presentación del producto se diseñaron envases adecuados en el que se adiciono una etiqueta con las respectivas propiedades, contenido, ingredientes, fecha de elaboración, fabricante, lugar de producción y responsable para las mermeladas y para la harina se lo hizo mediante fundas de un $\mathrm{kg}$ de alta densidad y se diseñó una etiqueta con datos referentes al contenido, fabricante y lugar de producción, responsable, fecha de elaboración; así como una receta para elaborar coladas, además se hace conocer el contenido nutritivo de la misma.

La publicidad y promoción se efectuaron en dos eventos como la Casa Abierta y en la VI Expo feria Agropecuaria, donde se entregaron probadores para la degustación, estas actividades permitieron realizar los análisis organolépticos de los productos y su venta final. También se diseñaron paneles con grupos de profesores, estudiantes y trabajadores para reforzar estos análisis, comprobándose que existió gran aceptación de los derivados de melloco. Además existió un gran interés tanto de los agricultores como de los consumidores por que se fomente en base a los derivados una empresa. Cabe señalar que la presencia de los medios de comunicación a los eventos realizados en Loja fue muy importante ya que permitieron difundir este trabajo. Del mismo modo se entregaron hojas volantes con las principales características de los tubérculos.

De igual forma se realizaron formulaciones con la harina de melloco, como coladas y sopas; realizándose comparaciones con diferentes tipos de harinas existentes en el mercado, siendo necesario realizar análisis organolépticos, en donde los catadores analizaron aspectos como color, sabor y viscosidad (espesamiento), dando preferencia finalmente a los elaborados con la harina de melloco.

\section{Conclusiones}

Como resultados del estudio de mercado se elaboraron mermeladas, harina y hojuelas de melloco mejorando su sabor original y optimizando sus características organolépticas. 
Se puede emprender en una microempresa procesadora de derivados de melloco representando un aumento en las ganancias incrementándose el valor agregado.

Las mermeladas de melloco con babaco, con la relación de la pulpa / azúcar 55/45 y pectina al 0,9\% presentaron excelentes características organolépticas en comparación con las mermeladas de melloco con uvilla obtenidas de la misma relación; puesto que la relación beneficio - costo (B/C) de 1,01 y 1,09 respectivamente, son bajas, la tasa interna de retorno (TIR) son altamente significativas por tratarse de productos con una alta velocidad de rotación del capital.

En relación a las cualidades organolépticas, las harinas fueron preferidas en los productos empleados, en especial por su olor agradable, textura poco fina y sabor característico. De los análisis obtenidos se desprende que al obtener harinas se eliminó un gran porcentaje de humedad que es del 84,47\% para el ecotipo blanco, 88,31\% ecotipo rojo y 86,56\% para el ecotipo verde.

En el transcurso de este proceso se evidenció que el 47,28\% de la población tiene un promedio de edad de 18 a 25 años, de los cuales el 52,31\% tiene un promedio ingreso mensual mayor a 350 USD, cuyo presupuesto menor al $25 \%$ lo empleo en el consumo de tubérculos, derivándose que existe una aceptable capacidad adquisitiva. Los eventos de capacitación y transferencias de tecnologías realizadas fueron de gran utilidad para los asistentes.

\section{Recomendaciones}

Consumir harina de melloco por ser altamente energético y por tener carbohidratos, además rica en minerales, vitaminas y poseer una cantidad apreciable de proteínas y pobre en grasas. Se han establecido los parámetros óptimos de secado (temperatura 70 grados centígrados y espesor de la hojuela $3 \mathrm{~mm}$ ), para los tres ecotipos, que pueden servir como referencias para la proyección de una industria en esta línea o para establecer regímenes para otros productos.

El envasado de la harina en fundas de alta densidad, soporta satisfactoriamente el almacenamiento al ambiente, por un lapso suficiente de tiempo para poder comercializarse. Sin embargo la utilización de empaques para las fundas, prolongaría mucho más el tiempo de almacenamiento y las protegería de daños.

Con la industrialización del melloco, podría proveerse de este valioso recurso, a las regiones marginales por la vialidad que carecen de este producto, o que tiene que pagar elevados costos de transporte. Actualmente no existe un mercado externo e interno para la elaboración de derivados de melloco, de manera que si se llegara a satisfacer esta demanda, se lograría una fuente de divisas y de trabajo para la población indígena de Saraguro.

\section{Bibliografía}

Abrigo, P. A. A. (2016). Identificación de Necesidades para Proponer el Desarrollo Turístico en la Comunidad de Tuncarta, del Cantón Saraguro de la Provincia de Loja. INNOVA Research Journal, 1(6). 
Abrigo, P. A. A. (2016). La fertilización orgánica del melloco (Ullucus tuberosus L.) y su rentabilidad en la comunidad de Tuncarta. INNOVA Research Journal, 1(12).

Apolo, V. (2000). Guía técnica: Procesamiento y/o transformación de alimentos. Área de Pequeñas Industria. AARNR, UNL. 30 p.

Espinosa, P; C. Crissman. (1997). Raíces y tubérculos andinos: Consumo, Aceptabilidad, Procesamiento. Departamento de Ciencias Sociales (CIP). Editorial Abya-Yala. Quito, Ecuador. 135 p.

Robles, E. (1981). Origen y Evaluación de la oca, ulluco y mashua. Centro de Informática para la Investigación Agrícola. Lima, Perú, Universidad Agraria La Molina, Lima, p. 17.

Ramon, S. (2012). Influencia lunar en la brotación de tubérculos de melloco (Ullucus tuberosus). Tesis Ing. Agrop. Universidad Técnica Estatal de Quevedo. Facultad de Ingeniería Agropecuaria.

Secretaria Nacional de Planificación y Desarrollo. (2013). Plan nacional del buen vivir. Quito, Ecuador. 600 pp.

Sigcho, M. (2015). Redes de alimentos y producción artesanal en la parroquia Saraguro, cantón Saraguro: Un aporte al análisis de la soberanía alimentaria. 2015, 77 pp.

Vimos, C. (1981). Caracterización y evaluación preliminar agronómico de 90 entradas de melloco, 48 de oca y 36 de mashua del banco de germoplasma del INIAP. Tesis Ing. Ag. Riobamba, Escuela Politécnica del Chimborazo, Facultad de Ingeniería Agronómica. 288 p.

Armas Cevallos, D. D. (2016). Diseño y desarrollo de hojuelas deshidratadas de melloco (ullucus tuberosus loz) para consumo humano (Bachelor's thesis, Quito: Universidad de las Américas, 2016.). 